\title{
The effect of bystander cardiopulmonary resuscitation on the survival of out-of- hospital cardiac arrests: a systematic review and meta-analysis
}

\author{
Jianting Song ${ }^{1}$, Wenxiu Guo ${ }^{2}$, Xiaoguang Lu ${ }^{3 *}$ D, Xin Kang ${ }^{3}$, Yi Song ${ }^{3}$ and Dianbo Gong ${ }^{3}$
}

\begin{abstract}
Background: For many years, bystander cardiopulmonary resuscitation (BCPR) has been considered as a favorable factor to improve survival of out-of-hospital cardiac arrests (OHCAs). To examine the effect of BCPR on the survival of OHCAs and whether BCPR might also improve survival when the initial rhythm of OHCAs is limited, we performed a meta-analysis on published observational studies.

Methods: We did a systematic review to identify all studies published up to March, 2018, in any language, that reported the relation between BCPR and the survival of OHCAs. Using standard forms, two authors independently identified studies for inclusion and extracted information. The outcome was survival. Meta-regression was done to ascertain weighted factors for the outcomes.

Results: Data were extracted from 19 studies involving 232,703 patients. Firstly, pooled odds ratio (OR) from 16 cohort studies showed that BCPR was associated with improved chance of survival of OHCAs compared with NO-BCPR (OR 1.95, 95\% confidence interval [CI]: 1.66-2.30). Secondly, from 8 cohort studies of OHCAs whose initial rhythm is limited, the pooled OR was 2.10 (95\% Cl, 1.68-2.63) of 6 articles for shockable rhythm and $1.07(95 \% \mathrm{Cl}$, 0.37-3.13) of 2 articles for non-shockable rhythm. Meta-regression showed a relation between the survival of OHCAs and BCPR was influenced by area $(p<0.05)$.

Conclusions: Based on currently available evidence, the findings of this meta-analysis suggest that BCPR increases the survival of OHCAs, and it also help OHCAs whose initial rhythm is shockable. That is to say BCPR is also helpful when emergency department response time is short. Therefore global priority should be given to increasing the incidence of BCPR by evidence-based best practice.
\end{abstract}

Keywords: Bystander CPR, Initial rhythm, Out-of-hospital cardiac arrest, Meta-analysis

\section{Background}

Cardiac arrest (CA) is a sudden loss of blood flow resulting from the heart suddenly stops beating, and it usually causes death if not treated within minutes. There are many causes of cardiac arrest, and cardiogenic disease is the most common reason which accounting for $75-85 \%$ [1]. Although the survival of cardiovascular diseases has

\footnotetext{
*Correspondence: dllxg@126.com

${ }^{3}$ Department of Emergency Medicine, Affiliated Zhongshan Hospital of Dalian University, No. 6th Jiefang Street, ZhongShan District, Dalian city, Liaoning Province, China

Full list of author information is available at the end of the article
}

improved significantly over the past 30 years, the survival of out-of-hospital cardiac arrests (OHCAs) is not apparently increasing globally [2]. According to statistics 5 million people worldwide will suffer from out-of-hospital cardiac arrest (OHCA) every year, of which only $7 \%$ will survive $[3,4]$.

Low survival of OHCAs can be attributed to many factors of the chain of survival. Despite years of guidelines of each country for cardiopulmonary resuscitation and emergency cardiovascular care update, bystander cardiopulmonary resuscitation (BCPR) remains the most important factor to improve the survival of OHCAs [5].

(c) The Author(s). 2018 Open Access This article is distributed under the terms of the Creative Commons Attribution 4.0 International License (http://creativecommons.org/licenses/by/4.0/), which permits unrestricted use, distribution, and reproduction in any medium, provided you give appropriate credit to the original author(s) and the source, provide a link to the Creative Commons license, and indicate if changes were made. The Creative Commons Public Domain Dedication waiver (http://creativecommons.org/publicdomain/zero/1.0/) applies to the data made available in this article, unless otherwise stated. 
Some researchers found that the delay to defibrillation was increased with the development of times, possibly because heavier traffic and the lack of emergency resources [6]. This result made BCPR become a more important link of the the survival chain of OHCA.

In 1973, American Heart Association's decision to endorse cardiopulmonary resuscitation (CPR) training of the lay public give support to the concept of large-scale training in many regions [7], and then there was a lot of trainings of BCPR successively all over the world. The bystanders of BCPR refers to onlookers of the OHCAs without medical background, which include trained and untrained lay rescuers in our meta-analysis.

This systematic review aimed to summarize current research results on the survival of BCPR for OHCAs, and make further discussion of the mechanism of BCPR to improve the survival by limiting the initial rhythm of OHCAs. and assessed whether BCPR improved the outcome depending upon the initial rhythm of OHCAs.

\section{Materials and methods}

Search strategy and selection criteria

We followed the proposed MOOSE (Meta-Analysis of Observational Studies in Epidemiology) [8] guidelines to report the present meta-analysis. We conducted a search of published English-language articles through searched PubMed and Embase databases from the data of inception until March, 2018 with search terms like "out-of-hospital cardiac arrest", "out-of-hospital ventricular fibrillation/ ventricular tachycardia/asystole/pulseless electrical activity", "bystander cardiopulmonary resuscitation". Additionally, reference lists of every article were screened for further related publications. There were no restrictions on language, publication date or publication status.

Studies would be included if they agreed with the following criteria: 1) cohort design study; 2) containing BCPR and NO-BCPR, were done for adult patients with out-of-hospital cardiac arrest; 3) providing adjusted OR, and corresponding $95 \% \mathrm{CI}$, or the number of events that can calculate them.

In addition, studies which designed as case reports, systematic reviews or studies with mutual overlapping populations were excluded from this meta-analysis.

\section{Data extraction}

Two reviewers independently extracted the following data from each eligible study: first author's last name, year of publication, site of origin, study period, study design, patients' age, the number of cases and controls, adjusted OR, statistical adjustments of confounding factors. Survival to discharge was the primary outcome variable, if data of survival to hospital discharge were not available, we used 30-day survival as the primary outcome. Any disagreements were resolved by consensus.

\section{Methodological quality assessment}

The risk of bias was analyzed according to NewcastleOttawa Scale (NOS) for cohort studies, which consists of three parameters of quality: selection, comparability, and outcome assessment. NOS assigns a maximum score of 4 for selection, 2 for comparability, and 3 for outcome. Hence, a score of 9 is the highest and reflects the highest quality.

\section{Data synthesis and analysis}

Firstly, we computed a pooled OR and $95 \%$ CI by using Stata 12.0 to generate forest plots, to determine whether there was a statistical association between BCPR and survival and to assess heterogeneity of studies for all OHCAs. Heterogeneity was quantified evaluated using the chi-square based Cochran's Q statistic [9] and the $\mathrm{I}^{2}$ statistic, this statistic yields results ranging from 0 to $100 \%\left(\mathrm{I}^{2}=0-25 \%\right.$, no heterogeneity; $\mathrm{I}^{2}=25-50 \%$, moderate heterogeneity; $\mathrm{I}^{2}=50-75 \%$, large heterogeneity; and $\mathrm{I}^{2}=75-100 \%$, extreme heterogeneity) [10]. If heterogeneity existed, the random effects model was used, otherwise, the fixed effects model was used. In addition, we analyzed which factors influence heterogeneity by meta-regression analysis. If significant heterogeneity is identified, subgroup analysis was also conducted according to the result of meta-regression. If possible, potential publication bias was assessed by visual inspection of the funnel plots of the primary outcome [11]. The Begg rank correlation test was used to examine the asymmetry of the funnel plot [12] and the Egger weighted linear regression test was used to examine the association between mean effect estimate and its variance [11], $P<0.05$ indicated bias, and $P>0.05$ indicated no publication bias. All statistical calculations were performed by Stata 12.0.

Secondly, we computed a pooled OR and $95 \%$ CI to present the effect of BCPR for patients whose initial rhythms are shockable and non-shockable respectively, and calculated heterogeneity with the method mentioned above. If heterogeneity existed, the random effects model was also used here.

\section{Results}

\section{Literature search and selection}

The search strategy generated 19 references: PubMed $(N=934)$, Embase $(N=340)$. After 170 duplicates discarded, we excluded publications based on titles and/or abstracts, mainly because they are reviews, animal studies, case reports, editorials, letters, comments and conference abstracts. 167 full-text studies were identified for further assessment. Subsequently, studies were excluded in line with the principle of PICOS (PatientsIntervention-Comparison-Outcome-Study Style). Among these studies, we excluded 144 studies which are mainly 
irrelevant to the PICOS: the characteristics of patients (28 studies) including only pediatric patients and OHCA with a non-cardiac cause, intervention (24 studies) including the comparison of the use of rescue drugs/the rescue method/the time when the onlookers started CPR/where the cardiac arrest occurred/whether there is a dispatcher-assisted BCPR, comparison (26 studies) including no control group/no relevant comparison, outcome (11 studies) including neurologic outcome/ mortality/return of spontaneous circulation, study style (42 studies), studies where data could not be extracted (7 studies), and duplicate reports (6 studies). Since all of our included studies are observational studies, and the survival of OHCAs is the result influenced by multiple factors, considering the confounding factors is very important to study the effect of BCPR. Therefore, this meta-analysis excludes 4 articles that do not consider confounding factors [13-16]. Finally, 19 articles were included. A flow chart showing the study selection is presented in Fig. 1.

\section{Description of the studies}

The characteristics of 19 prospective/retrospective cohort studies are presented in Table 1. These studies were published from 1985 to 2017. Firstly, there are 16 articles studied BCPR for all OHCAs, which include eight studies were conducted in Europe [17-24], 3 in Asia [25-27], 4 in America [28-31], 1 in Oceania [32]. The sizes of the cohorts ranged from 722 to 66,780 . There are two ORs in one article [21], one from 1992 to 1995 and the other from 2002 to 2005. Secondly, 8 articles reported OHCA whose initial rhythm were shockable or non-shockable, 6 $[6,24,25,29,32,33]$ for shockable rhythm, only $2[33,34]$ for non-shockable rhythm.

\section{Quality of the included studies}

There was good agreement between the reviewers in regards to the validity assessments, the quality assessment of all the published studies were shown in Table 2 . All of the studies were of high quality (NOS score higher than 6). In terms of population selection bias, none of the articles from Africa fitted our inclusion criteria. Selection bias is likely because of unpublished data, abstracts, and presentations were not included. In terms of comparability bias, most studies included adequate matching or adjustments for covariates such as emergency medical services (EMS) response interval and the patients' age and so on. The most common outcome bias was the lack of blinding.

\section{Effects of interventions Survival of all OHCAs}

Sixteen studies prospectively or retrospectively investigated the association between BCPR and survival of OHCAs. Meta-analysis of these studies showed a significantly increased chance of survival with BCPR comparing

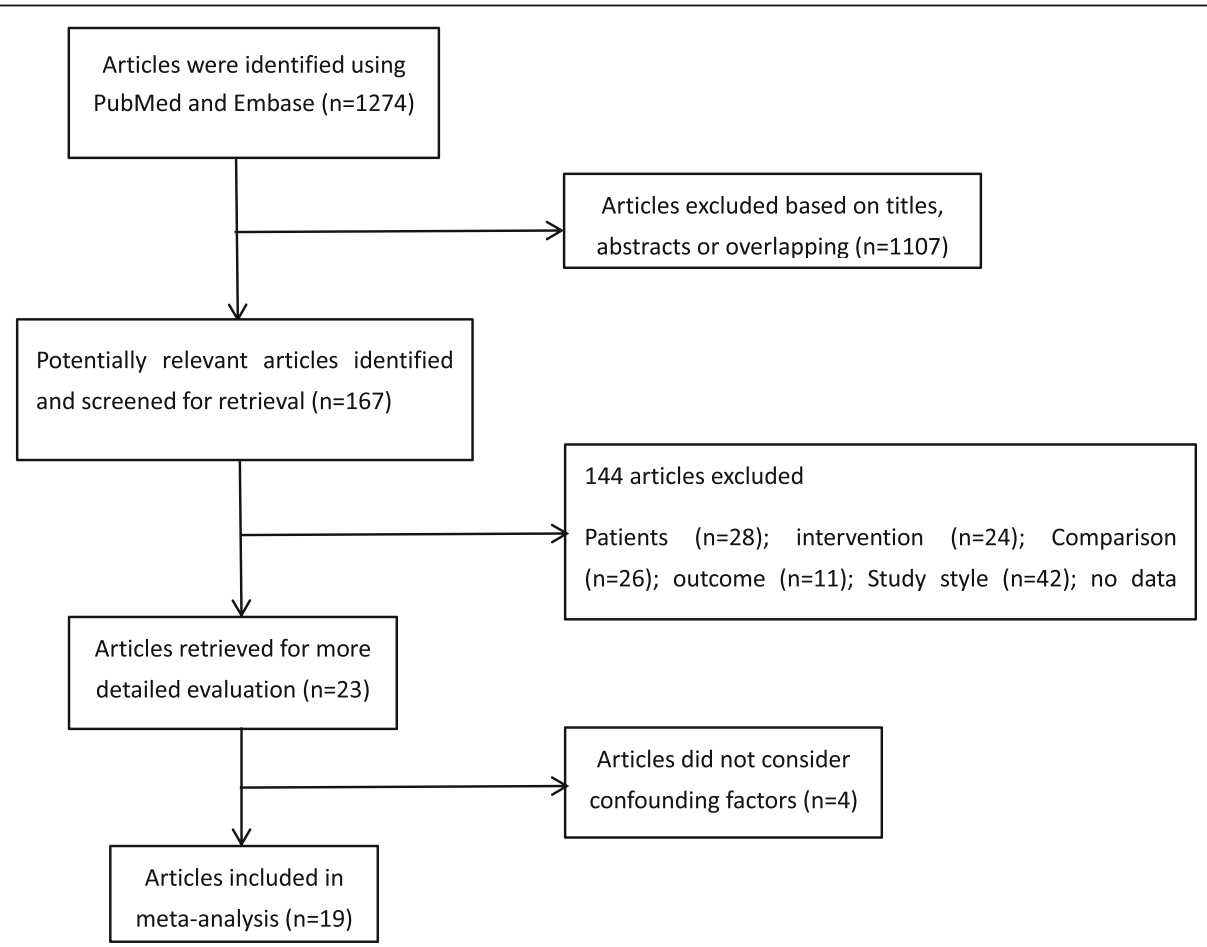

Fig. 1 Summary of the studies selection process 


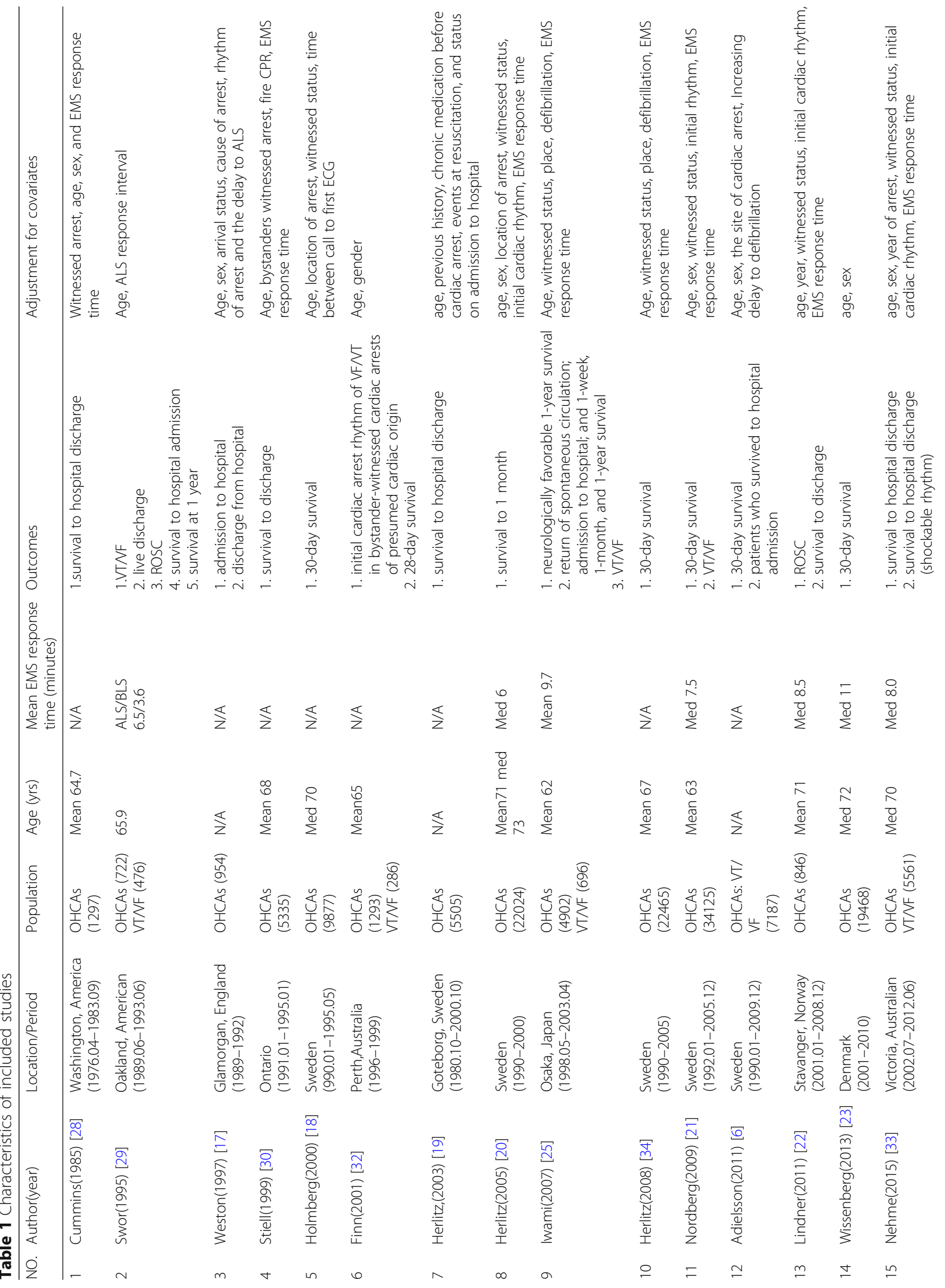




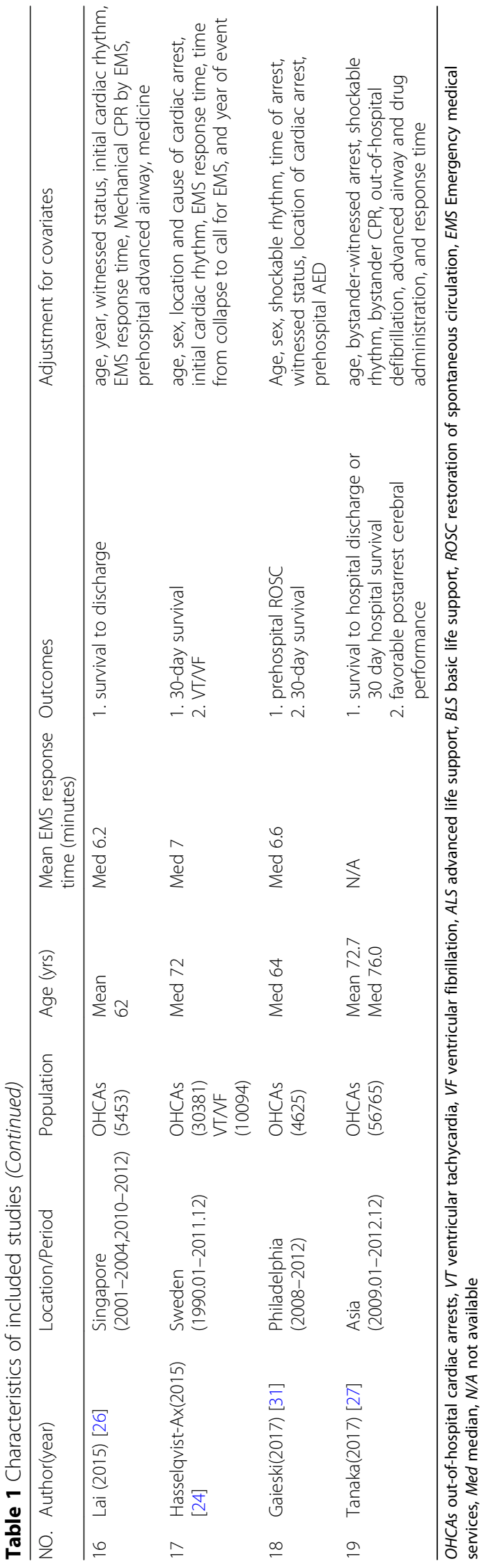


Table 2 Quality assessment according to the Newcastle-Ottawa Scale

\begin{tabular}{lllll}
\hline Study & Selection & Comparability & Outcome & Total \\
\hline Cummins(1985) & 4 & 2 & 2 & 8 \\
Swor(1995) & 4 & 2 & 2 & 8 \\
Weston(1997) & 3 & 2 & 2 & 7 \\
Stiell(1999) & 3 & 2 & 2 & 7 \\
Holmberg(2000) & 3 & 2 & 2 & 7 \\
Finn(2001) & 4 & 1 & 2 & 7 \\
Herlitz(2003) & 3 & 1 & 2 & 6 \\
Herlitz(2005) & 4 & 2 & 2 & 8 \\
Iwami(2007) & 4 & 2 & 2 & 8 \\
Herlitz(2008) & 3 & 2 & 2 & 7 \\
Nordberg(2009) & 3 & 2 & 2 & 7 \\
Lindner(2011) & 3 & 2 & 2 & 7 \\
Wissenberg(2013) & 4 & 1 & 2 & 7 \\
Lai(2015) & 3 & 2 & 2 & 7 \\
Nehme(2015) & 3 & 2 & 2 & 7 \\
Hasselqvist-Ax(2015) & 4 & 2 & 2 & 8 \\
Gaieski(2017) & 4 & 2 & 2 & 8 \\
Tanaka(2017) & 4 & 2 & 2 & 8 \\
\hline & & & &
\end{tabular}

with NO-BCPR (Fig. 2) (OR: 1.95; 95\%CI: 1.66-2.30; $P<0.05)$. Substantial heterogeneity was observed $(P<0.001$; $\left.\mathrm{I}^{2}=86.8 \%\right)$

\section{Survival of OHCAs whose initial rhythm is shockable}

6 studies reported the association between BCPR and survival of OHCAs whose initial rhythm was shockable, giving a total sample of 24,300 participants. The data was analyzed by using a random-effects model according to the heterogeneity test result $\left(P=0.013, \mathrm{I}^{2}=65.3 \%\right)$. There was a significant difference between BCPR and NO-BCPR in patients whose initial rhythm is shockable with the OR of 2.10 (95\%CI, 1.68-2.63, $P<0.05)$ (Fig. 3).

\section{Survival of OHCAs whose initial rhythm is non-shockable}

2 studies demonstrated the relationship between BCPR and the survival of OHCAs whose initial rhythm was non-shockable. A random-effects model was also used here. However, the ORs for the association varied from 0.62 to 1.85 across studies. Overall, no difference was recorded between BCPR and NO-BCPR for OHCAs of which initial rhythm is non-shockable (OR: 1.07 [95\%CI, 0.37 to 3.13 ]; $P>0.05)$. Substantial heterogeneity was observed $\left(P<0.001, \mathrm{I}^{2}=96.2 \%\right)$ (Fig. 3$)$.

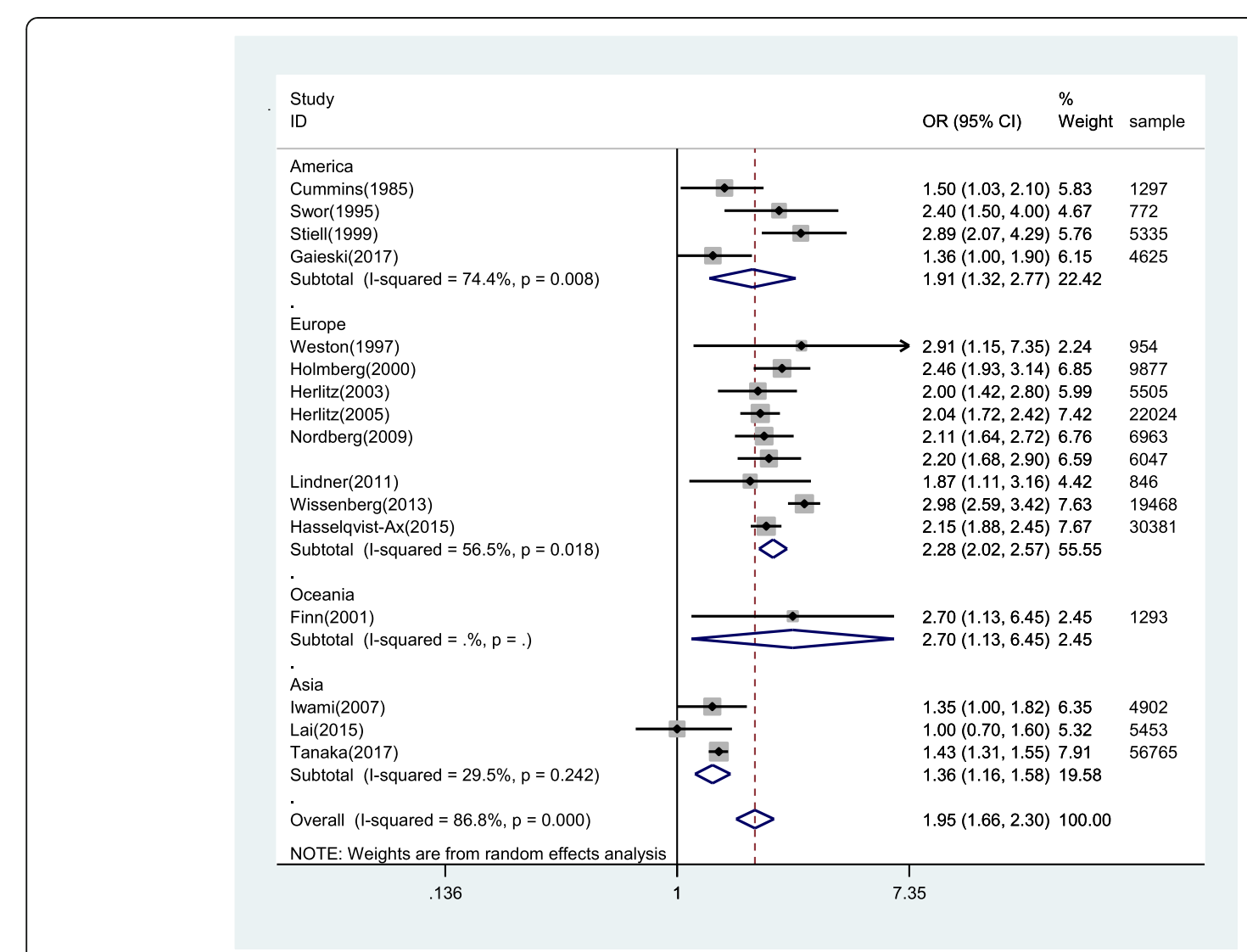

Fig. 2 Forest plot of studies reporting BCPR stratified by area 


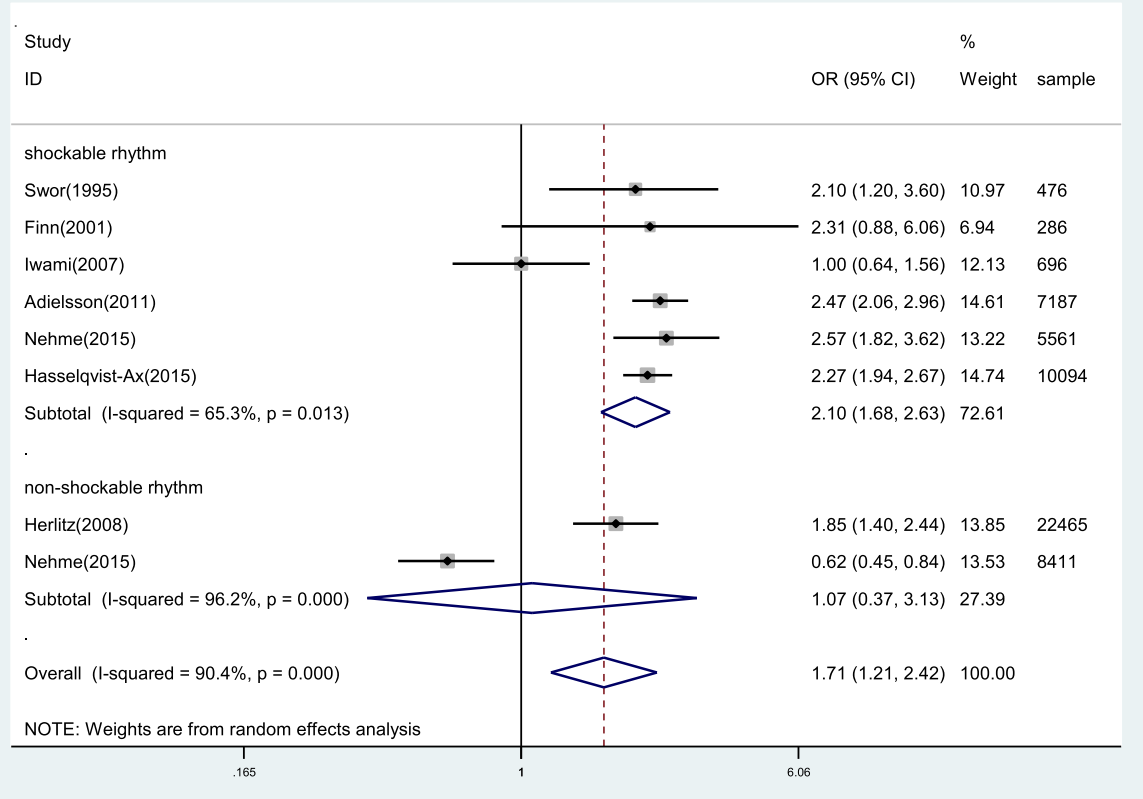

Fig. 3 Forest plot of studies reporting BCPR stratified by initial rhythm

\section{Regression and subgroup analyses}

Meta-regression analyses were conducted to assess predictors of heterogeneity among odds ratios. Through multiple meta-regression analyses, area may lead to heterogeneity among the possible heterogeneity factors(years, area, outcome index) (Table 3). Then subgroup analysis was conducted according to regional differences (Fig. 2).

\section{Publication Bias}

Figure 4 showed that the funnel plot was symmetrical, that indicated there was no publication bias existed. The Begg rank correlation test and Egger linear regression test also indicated no evidence of publication bias

Table 3 Meta-regression analysis of Included Studies

\begin{tabular}{ll}
\hline VARIABLES & $y$ \\
\hline Outcome & 0.298 \\
& -0.19 \\
Year & -0.00502 \\
Area & -0.0104 \\
& $-0.150+$ \\
Constant & -0.0636 \\
& 10.5 \\
Observations & -20.66 \\
\hline
\end{tabular}

Notes_Titles: $\neq p<0.01,+p<0.05,{ }^{*} p<0.1$ among studies of BCPR and the survival of OHCAs. (Begg, $p=0.827$; Egger, $p=0.439$ )

\section{Discussions}

A timely and effective cardiopulmonary resuscitation can improved survival of OHCAs, and we all know that closed chest CPR can save the patients who suffered from cardiac arrest since 1960s. However, there was no systematic review or meta-analysis evaluating the effect of BCPR by limiting the initial rhythm of OHCAs. The initial rhythm of cardiac arrest is classified into "shockable" versus "non-shockable", as determined by the electrocardiograph (ECG) rhythm. This refers to whether a cardiac dysrhythmia can be treatable by using defibrillation. The two "shockable" rhythms are ventricular fibrillation(VF) and pulseless ventricular tachycardia(VT) while the two "nonshockable" rhythms are asystole and pulseless electrical activity. However, the most important finding of our study is that BCPR can improve the survival of OHCAs whose initial rhythm is shockable rhythm.

So, our meta-analysis was conducted for OHCAs by limiting and no-limiting initial rhythm to show the significance of $B C P R$ and discuss further the mechanism of BCPR improving the survival of OHCAs.

Not surprisingly, when no-limiting the initial rhythm, our results, which BCPR improved the survival of OHCAs [35], were the same as those of previous studies in animals and studies including registry data. Its mechanism, which demonstrated by many epidemiological 


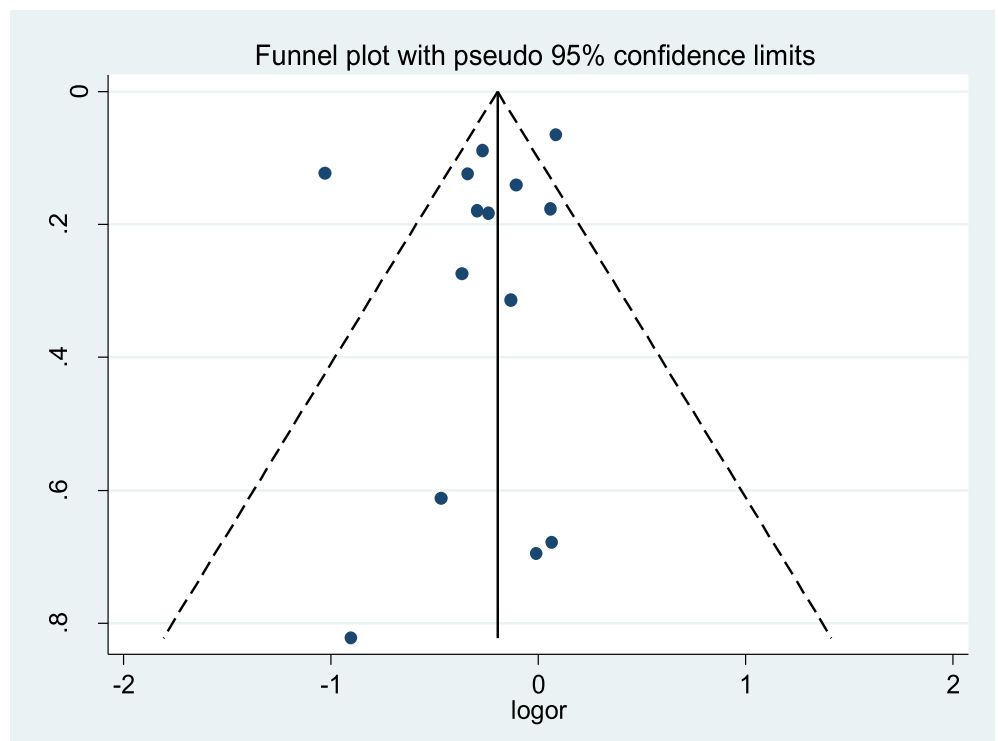

Fig. 4 Funnel plot based on Odds Ratio for association between BCPR and the survival of OHCAs

surveys [29, 36-39], may be prolonging the time window for defibrillation to maintain more shockable rhythm as the initial rhythm when EMS arrived, since the outcome of OHCA is strongly related to whether or not the patient has shockable rhythms when the EMS arrives [16, 40].

When limiting the initial rhythm, our results demonstrated that BCPR still had a good survival compared with NO-BCPR when the initial rhythm of OHCAs was shockable. So we assumed that BCPR not only prolonged the shockable rhythm, but also played other roles for OHCAs. It is possible to keep more cardiomyocytes alive while maintaining the initial rhythm.

For the patients whose initial rhythm is non-shockable, the result of this meta-analysis should be made a further confirmation by more researches and epidemiological surveys.

Some previous articles have demonstrated that BCPR has no effect on patients whose initial rhythm is shockable when EMS arrived. The results of our meta-analysis denied this conclusion and showed BCPR's effect on VT/ VF. Three-phase model of ventricular fibrillation [41] also showed that in the circulatory phase, chest compression could improve the blood supply of myocardium and it took priority over defibrillation. In a word, CPR also has positive effect on the patients whose initial rhythm is VT/VF.

Through multiple meta-regression analysis we concluded that the region was a factor that affects heterogeneity. Previous epidemiological survey [3] also showed that North America had the highest incidence of resuscitation for cardiac arrest and Asia had the lowest percentage of VF and the lowest survival rates. Comparing with America and Europe, popularizing BCPR in Asia is relatively late, so the quality of BCPR might be lower in Asia. And different emergency medical system in different country might also be a factor. Therefore, good experiences from America and Europe should be learned by Asia and other regions. For example, in terms of CPR training, "cascade" training [18] which means instructor trainers train instructors who then train rescuers in their turn might be a good method to make more people accountable, video-based training [42] might be a good way to transmit the right message to more people and easy to deliver, and making CPR training become mandatory might be helpful too. As for increasing the incidence of BCPR, telemedicine and dispatcher assisted CPR [43, 44] might be an effective method.

Because of the simplicity and non-invasive of standard $\mathrm{CPR}$, it is not just a medical practice but a common practice for everyone. Since BCPR has an irreplaceable role in improving the survival of OHCAs, we should pay more attention to increasing the incidence of cardiopulmonary resuscitation and ensuring the quality of cardiopulmonary resuscitation.

A major strength of our study is that this is the first systematic review/meta-analysis which evaluates the effect of BCPR by limiting and no-limiting initial rhythm. Moreover, the number of participants was a relatively large sample size to clarify and confirm this issue. In addition, we strictly enforce the literature search, data extraction and analysis, in order to ensure the credibility of our results.

\section{Limitations}

However, several limitations should be acknowledged. The first is the substantial heterogeneity among included 
articles. The organization of each country's emergency system is different, so that the first aid measure provided by them is also different. And the quality of BCPR in each region is uneven due to the different degree of training and emphasis. Some studies suggest that high quality BCPR by professionals is more effective, and ventricular fibrillation as initial rhythm is more common than ordinary bystanders [21]. Nevertheless, in the majority of studies in this meta-analysis, no data were available whether the bystander had been trained in cardiopulmonary resuscitation or not, so we were unable to measure the quality of the BCPR. The second is that the articles which are about OHCAs whose initial rhythm is non-shockable rhythm are less, therefore, the authenticity of the result remains to be confirmed.

\section{Conclusions}

Our meta-analysis provides evidence suggesting that BCPR not only plays an important role for OHCAs including the initial rhythm of OHCAs is shockable rhythm when EMS arrived. But also works for patients whose initial rhythm is shockable. However, the findings should be interpreted cautiously in line with the overall methodological quality and potential biases of the included trials. More clinical studies and basic trials are necessary for further evaluation of the effectiveness of $\mathrm{BCPR}$ and exploration the mechanism by which BCPR improves the survival.

\section{Abbreviations \\ BCPR: Bystander cardiopulmonary resuscitation; CA: Cardiac arrest; Cl: Confidence interval; CPR: Cardiopulmonary resuscitation; \\ ECG: Electrocardiograph; EMS: Emergency medical services; MOOSE: Meta- Analysis of Observational Studies in Epidemiology; NOS: Newcastle-Ottawa Scale; NSFC: Natural Science Foundation of China; OHCAs: Out-of-hospital cardiac arrests; OR: Odds ratio; PICOS: Patients-Intervention-Comparison- Outcome-Study Style; VF: Ventricular fibrillation; VT: Ventricular tachycardia}

\section{Funding}

This study was supported by three funds from Natural Science Foundation of China (NSFC) (no.81673801 and no. 81173397 and no. 81473512).

\section{Authors' contributions}

The study was conceived and designed by XL, JS and WG independently screened literature, extracted data, and evaluated study quality. Disagreements between JS and WG were determined by XL, JS conducted data synthesis and analysis and wrote the paper. XL, XK and YS checked this work again. DG and YS participated in the discussion. All authors read and approved the final manuscript.

\section{Ethics approval and consent to participate}

Not applicable.

\section{Consent for publication}

Not applicable.

\section{Competing interests}

There is no competing interests for publication of this paper.

\section{Publisher's Note}

Springer Nature remains neutral with regard to jurisdictional claims in published maps and institutional affiliations.

\section{Author details}

'Dalian Medical University, No. 9, west section, Lushun South road, Dalian city, Liaoning Province, China. ${ }^{2}$ Liaoning university of Traditional Chinese Medicine, No. 79, Chongshan road, Huanggu District, Shenyang city, Liaoning province, China. ${ }^{3}$ Department of Emergency Medicine, Affiliated Zhongshan Hospital of Dalian University, No. 6th Jiefang Street, ZhongShan District, Dalian city, Liaoning Province, China.

Received: 5 July 2018 Accepted: 24 September 2018

Published online: 11 October 2018

\section{References}

1. Kuisma M, Alaspaa A. Out-of-hospital cardiac arrests of non-cardiac origin Epidemiology and outcome. Eur Heart J. 1997;18:1122-8.

2. Sasson C, Rogers MA, Dahl J, Kellermann AL. Predictors of survival from outof-hospital cardiac arrest: a systematic review and meta-analysis. Circulation Cardiovascular quality and outcomes. 2010;3:63-81.

3. Berdowski J, Berg RA, Tijssen JGP, Koster RW. Global incidences of out-ofhospital cardiac arrest and survival rates: systematic review of 67 prospective studies. Resuscitation. 81:1479-87.

4. Nishiyama C, Brown SP, May S, Iwami T, Koster RW, Beesems SG, Kuisma M, Salo A, Jacobs I, Finn J, Sterz F, Nurnberger A, Smith K, Morrison L, Olasveengen TM, Callaway CW, Shin SD, Grasner JT, Daya M, Ma MH, Herlitz J, Stromsoe A, Aufderheide TP, Masterson S, Wang H, Christenson J, Stiell I, Davis D, Huszti E, Nichol G. Apples to apples or apples to oranges? International variation in reporting of process and outcome of care for outof-hospital cardiac arrest. Resuscitation. 2014;85:1599-609.

5. Leong BS. Bystander cpr and survival. Singap Med J. 2011;52:573-5.

6. Adielsson A, Hollenberg J, Karlsson T, Lindqvist J, Lundin S, Silfverstolpe J, Svensson L, Herlitz J. Increase in survival and bystander cpr in out-ofhospital shockable arrhythmia: Bystander cpr and female gender are predictors of improved outcome Experiences from sweden in an 18-year perspective. Heart (British Cardiac Society). 2011;97:1391-6.

7. American Heart A. Guidelines for cardiopulmonary resuscitation (cpr) and emergency cardiac care (ecc). JAMA. 1974;227:833-68.

8. Stroup DF, Berlin JA, Morton SC, Olkin I, Williamson GD, Rennie D, Moher D, Becker BJ, Sipe TA, Thacker SB. Meta-analysis of observational studies in epidemiology: a proposal for reporting. Meta-analysis of observational studies in epidemiology (moose) group. JAMA. 2000;283:2008-12.

9. Higgins JP, Thompson SG. Quantifying heterogeneity in a meta-analysis. Stat Med. 2002;21:1539-58.

10. Higgins JP, Thompson SG, Deeks JJ, Altman DG. Measuring inconsistency in meta-analyses. BMJ (Clinical research ed) 2003. 327:557-60.

11. Egger M, Davey Smith G, Schneider M, Minder C. Bias in meta-analysis detected by a simple, graphical test. BMJ (Clinical research ed) 1997. 315: 629-34.

12. Begg $C B$, Mazumdar M. Operating characteristics of a rank correlation test for publication bias. Biometrics. 1994;50:1088-101.

13. Lund I, people SAC r b I. Lancet (London, England). 1976;2:702-4.

14. Eisenberg M, Bergner $L$, Hallstrom A. Paramedic programs and out-ofhospital cardiac arrest: I. factors associated with successful resuscitation. Am J Public Health. 1979;69:30-8.

15. Guzy PM, Pearce ML, Greenfield S. The survival benefit of bystander cardiopulmonary resuscitation in a paramedic served metropolitan area. Am J Public Health. 1983;73:766-9.

16. Roth R, Stewart RD, Rogers K, Cannon GM. Out-of-hospital cardiac arrest: factors associated with survival. Ann Emerg Med. 1984;13:237-43.

17. Weston CF, Wilson RJ, Jones SD. Predicting survival from out-of-hospital cardiac arrest: a multivariate analysis. Resuscitation. 1997;34:27-34.

18. Holmberg M, Holmberg S, Herlitz J. Effect of bystander cardiopulmonary resuscitation in out-of-hospital cardiac arrest patients in Sweden. Resuscitation. 2000:47:59-70.

19. Herlitz J, Bang A, Gunnarsson J, Engdahl J, Karlson BW, Lindqvist J, Waagstein L. Factors associated with survival to hospital discharge among patients hospitalised alive after out of hospital cardiac arrest: change in outcome over 20 years in the community of goteborg, Sweden. Heart. 2003:89:25-30.

20. Herlitz J, Svensson L, Holmberg S, Angquist KA, Young M. Efficacy of bystander cpr: intervention by lay people and by health care professionals. Resuscitation. 2005;66:291-5. 
21. Nordberg P, Hollenberg J, Herlitz J, Rosenqvist M, Svensson L. Aspects on the increase in bystander cpr in Sweden and its association with outcome Resuscitation. 2009:80:329-33.

22. Lindner TW, Søreide E, Nilsen OB, Torunn MW, Lossius HM. Good outcome in every fourth resuscitation attempt is achievable-an utstein template report from the Stavanger region. Resuscitation. 2011:82:1508-13.

23. Wissenberg M, Folke F, Weeke P, Hansen CM, Olesen J, Lindhardsen J, Lippert F, Gislason G, Nielsen SL, Kober L, Torp-Pedersen C. Improved survival and increase in bystander cardiopulmonary resuscitation after outof-hospital cardiac arrest: a nationwide cohort study 2001-2010. J Am Coll Cardiol. 2012;59:E1896.

24. Hasselqvist-Ax I, Riva G, Herlitz J, Rosenqvist M, Hollenberg J, Nordberg P, Ringh M, Jonsson M, Axelsson C, Lindqvist J, Karlsson T, Svensson L. Early cardiopulmonary resuscitation in out-of-hospital cardiac arrest. N Engl J Med. 2015:372:2307-15.

25. Iwami T, Kawamura T, Hiraide A, Berg RA, Hayashi Y, Nishiuchi T, Kajino K, Yonemoto N, Yukioka H, Sugimoto H, Kakuchi H, Sase K, Yokoyama H, Nonogi $\mathrm{H}$. Effectiveness of bystander-initiated cardiac-only resuscitation for patients with out-of-hospital cardiac arrest. Circulation. 2007;116:2900-7.

26. Lai H, Choong CV, Fook-Chong S, Ng YY, Finkelstein EA, Haaland B, Goh ES, Leong BS, Gan HN, Foo D, Tham LP, Charles R, Ong ME. Interventional strategies associated with improvements in survival for out-of-hospital cardiac arrests in Singapore over 10 years. Resuscitation. 2015;89:155-61.

27. Tanaka H, Ong MEH, Siddiqui FJ, Ma MHM, Kaneko H, Lee KW, Kajino K, Lin CH, Gan HN, Khruekarnchana P, Alsakaf O, Rahman NH, Doctor NE, Assam P, Shin SD. Modifiable factors associated with survival after out-of-hospital cardiac arrest in the pan-asian resuscitation outcomes study. In: Annals of emergency medicine; 2017.

28. Cummins RO, Eisenberg MS, Hallstrom AP, Litwin PE. Survival of out-ofhospital cardiac arrest with early initiation of cardiopulmonary resuscitation. Am J Emerg Med. 1985;3:114-9.

29. Swor RA, Jackson RE, Cynar M, Sadler E, Basse E, Boji B, Rivera-Rivera EJ, Maher A, Grubb W, Jacobson R, et al. Bystander cpr, ventricular fibrillation, and survival in witnessed, unmonitored out-of-hospital cardiac arrest. Ann Emerg Med. 1995;25:780-4.

30. Stiell IG, Wells GA, DeMaio VJ, Spaite DW, Field BJ 3rd, Munkley DP, Lyver $M B$, Luinstra LG, Ward R. Modifiable factors associated with improved cardiac arrest survival in a multicenter basic life support/defibrillation system: opals study phase i results. Ontario prehospital advanced life support. Ann Emerg Med. 1999;33:44-50.

31. Gaieski DF, Agarwal AK, Abella BS, Neumar RW, Mechem C, Cater SW, et al. Adult out-of-hospital cardiac arrest in Philadelphia from 2008-2012: an epidemiological study. Resuscitation. 2017;115:17-22

32. Finn JC, Jacobs IG, Holman CD, Oxer HF. Outcomes of out-of-hospital cardiac arrest patients in Perth, Western Australia, 1996-1999. Resuscitation. 2001;51:247-55.

33. Nehme Z, Bernard S, Cameron P, Bray J, Meredith I, Lijovic M, Smith K. Using a cardiac arrest registry to measure the quality of emergency medical service care: a decade of findings from the victorian ambulance cardiac arrest registry. EMA - Emergency Medicine Australasia. 2015;27:18-9.

34. Herlitz J, Svensson L, Engdahl J, Silfverstolpe J. Characteristics and outcome in out-of-hospital cardiac arrest when patients are found in a non-shockable rhythm. Resuscitation. 2008;76:31-6.

35. Kitamura T, Iwami T, Kawamura T, Nitta M, Nagao K, Nonogi H, Yonemoto N, Kimura T. Nationwide improvements in survival from out-of-hospital cardiac arrest in Japan. Circulation. 2012;126:2834-43.

36. Waalewijn RA, Nijpels MA, Tijssen JG, Koster RW. Prevention of deterioration of ventricular fibrillation by basic life support during out-of-hospital cardiac arrest. Resuscitation. 2002;54:31-6.

37. Christenson J, Andrusiek D, Everson-Stewart S, Kudenchuk P, Hostler D, Powell J, Callaway CW, Bishop D, Vaillancourt C, Davis D, Aufderheide TP, Idris A, Stouffer JA, Stiell I, Berg R. Chest compression fraction determines survival in patients with out-of-hospital ventricular fibrillation. Circulation. 2009;120:1241-7.

38. Ritter G, Wolfe RA, Goldstein S, Landis JR, Vasu CM, Acheson A, Leighton R, Medendrop SV. The effect of bystander cpr on survival of out-of-hospital cardiac arrest victims. Am Heart J. 1985;110:932-7.

39. Herlitz J, Ekstrom L, Wennerblom B, Axelsson A, Bang A, Holmberg S. Type of arrhythmia at ems arrival on scene in out-of-hospital cardiac arrest in relation to interval from collapse and whether a bystander initiated cpr. Am J Emerg Med. 1996;14:119-23.
40. Gilmore CM, Rea TD, Becker $\amalg$, Eisenberg MS. Three-phase model of cardiac arrest: time-dependent benefit of bystander cardiopulmonary resuscitation. Am J Cardiol. 2006;98:497-9.

41. Vilke GM, Chan TC, Dunford JV, Metz M, Ochs G, Smith A, Fisher R, Poste JC, McCallum-Brown L, Davis DP. The three-phase model of cardiac arrest as applied to ventricular fibrillation in a large, urban emergency medical services system. Resuscitation. 2005;64:341-6.

42. Bystander cpr. A new video-based training program delivers the right message to the right people. JEMS. 2005;30:18-9.

43. Atkinson PR, Bingham J, McNicholl BP, Loane MA, Wootton R. Telemedicine and cardiopulmonary resuscitation: the value of video-link and telephone instruction to a mock bystander. J Telemed Telecare. 1999;5:242-5.

44. Bang A, Ortgren PO, Herlitz J, Wahrborg P. Dispatcher-assisted telephone cpr: a qualitative study exploring how dispatchers perceive their experiences. Resuscitation. 2002:53:135-51.

\section{Ready to submit your research? Choose BMC and benefit from:}

- fast, convenient online submission

- thorough peer review by experienced researchers in your field

- rapid publication on acceptance

- support for research data, including large and complex data types

- gold Open Access which fosters wider collaboration and increased citations

- maximum visibility for your research: over $100 \mathrm{M}$ website views per year

At BMC, research is always in progress.

Learn more biomedcentral.com/submissions 